\title{
Ecological state of water bodies and their water protection zones within the boundaries of settlements of the Yamal Peninsula
}

\author{
Roman Kolesnikov* \\ Arctic Research Center of the YNAD, 629007, Salekhard, Russian Federation
}

\begin{abstract}
Most of the population of the Yamal Peninsula lives in settlements located on the banks of rivers. The increasing industrial development of the Yamal Peninsula leads to the fact that in these settlements in the water area and on the shores, objects of the fuel and energy complex are being built and functioning. At the same time, the contribution to water pollution of settlements located here, as well as objects of transport and fuel and energy infrastructure, is still unclear. On the other hand, the issues of intensifying the processes of coastal destruction and the related danger to residential and economic infrastructure are increasingly being discussed. However, the degree of activation of these processes on the Yamal Peninsula is also poorly understood. During the study, the state of water bodies and water protection zones was monitored for the period from 2016 to 2020. It was found that at present no significant anthropogenic pollution of water and bottom sediments is recorded. The content of pollutants and heavy metals is mainly determined by natural conditions. At the same time, the water protection zones are littered with scrap metal and household waste. Activation of channel processes and processes of abrasion and thermal abrasion of the banks is observed. The intensity of coastal destruction processes in the erosion zone varies from 0.25 to $0.85 \mathrm{~m} /$ year.
\end{abstract}

\section{Introduction}

The Yamal Peninsula, located in the north of Western Siberia, is a unique territory where active industrial development (extraction of hydrocarbons, construction of point, linear and areal facilities) is combined with traditional activities of the indigenous population of the North (reindeer husbandry, fishing, hunting). For a long time, shift workers of oil and gas enterprises, a nomadic tundra population and a population leading a sedentary lifestyle in rural areas have been compactly living here. Over the past several decades, large industrial complexes have been formed on the Yamal Peninsula, and territories are being urbanized $[1,2]$, which leads to a strong impact on terrestrial and aquatic ecosystems.

Due to the fact that most settlements, industrial and transport infrastructure are located on the shores of water bodies (including the Guba $\mathrm{Ob}$ ), and pipelines are laid along the

\footnotetext{
*Corresponding author: roman387@mail.ru
} 
bottom, they are subject to serious anthropogenic pressure. The settlements located on the banks of the rivers of the Yamal Peninsula and the Ob Guba do not have treatment facilities; therefore, untreated wastewater flows into water bodies [3, 4].

In addition to the anthropogenic impact, under the conditions of the changing climate and the specific geological structure of the peninsula (it is composed of permafrost rocks of light granulometric composition), channel processes have intensified, which lead to the destruction of the banks and pose a threat to residential and industrial facilities located on them.

All of the above determines the relevance of water monitoring and study of the ecological state of water bodies and their water protection zones. This is what became the main goal of the study.

\section{Object and research methods}

The object of the study was the water bodies and their water protection zones located within the settlements of the Yamal Peninsula: the Syoyaha river in the Syoyaha village, the Yanguta channel in the Panaevsk village, the Nadym Ob river in the Salemal village, the $\mathrm{Ob}$ Guba in the villages of Novyj Port and Mys Kamennyj (Fig. 1).

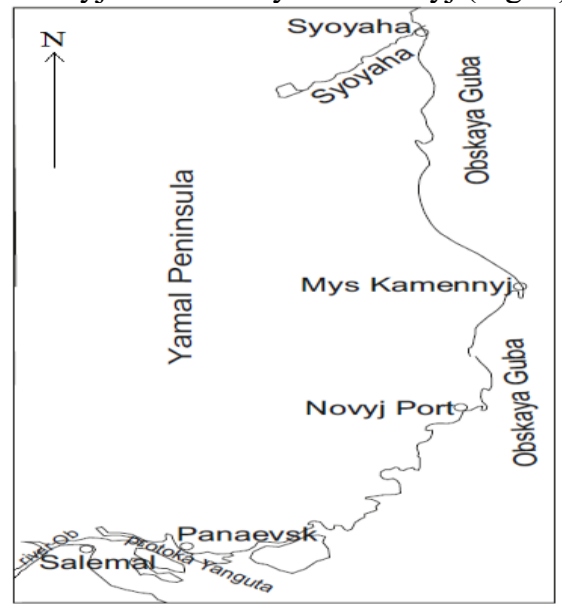

Fig. 1. Arrangement of the objects under study.

During the research, monitoring of the state of water protection zones, the mode of their use within the boundaries of settlements and morphometric features of water bodies was carried out; monitoring the condition of the banks of water bodies within the boundaries of settlements; monitoring the state of the bottom of water bodies; monitoring changes in the morphometric characteristics of a water body; geodetic surveying of coastlines. The monitoring was carried out from 2016 to 2020. The work used data collected personally by the author, as well as the results of water monitoring carried out by the government of the Yamalo-Nenets Autonomous Okrug. The content of total iron, manganese, ammonium nitrogen, nitrate nitrogen, nitrite ion, chloride ion, sulfate ion, oil products, zinc, copper, nickel, phenols were determined in water and bottom sediments by standard methods. In bottom sediments, the content of chromium, cadmium, lead, mercury, anionic surfactants and benzo (a) pyrene was additionally determined. The biological oxygen consumption, chemical oxygen consumption, and dissolved oxygen were measured in the water. Biotesting of toxicity of bottom sediments and surface waters was carried out. The toxicity index has been calculated. For a comprehensive assessment of the quality of surface water bodies, the specific combinatorial index of water pollution was calculated [5]. 


\section{Results}

The Yamal Peninsula is distinguished by extremely unfavorable natural and climatic conditions. For the rivers of the peninsula, the main natural factors that determine the modern dynamics of channel processes are the geological and geomorphological structure, climatic conditions for the formation of runoff, the development of denudation processes, and soil and vegetation cover.

In the studied areas, channel deformations occur under conditions of easily eroded soils, the presence of permafrost and prolonged flooding of the floodplain. The rivers have a slight slope of the channel. In this regard, deep erosion in river valleys is weak. Fluctuations in the width and depth of the channel depend on the level regime of the river.

Channel deformations in water bodies are of several types. On the Seyaha river, free meandering develops, in the section of the Nadym Ob river and the Yangut channel, there is a floodplain multi-arm. A weak manifestation of deformations was noted at the monitoring sites of the Ob Guba coast in the villages of Novyj Port and Mys Kamennyj. Here, the main factor of destruction is wind-wave action.

On a low, moderately steep, root slope of the coast of the village of Novyj Port, small blocks of subsidence and separation walls are noted. Most of the slope slides slowly. The soil accumulates on the sandbank. There are chaotic bank protection in the village. The average annual displacement of the coastal edge is $0.15-0.25 \mathrm{~m} /$ year. There is a potential danger of damage and destruction of outbuildings on the edge of the coast.

Within the monitoring sites of the villages of Panaevsk and Salemal, active deformations occur within the channel. The movement of channel forms and shoals is noted. Also, there is a displacement of the rods of the water flow, the introduction of reach areas and the formation of individual shoals. On the main slopes of the coast, abrasion processes are recorded as a result of wave action. The intensity of erosion in the erosion zone varies from 0.25 to $0.85 \mathrm{~m} /$ year. There is a danger to the integrity of the located communications, pipelines, road surface.

At the monitoring site in the village of Seyaha, strong channel deformations are recorded. The high bedrock bank, on which the settlement is located, is being destroyed. For over $850 \mathrm{~m}$, at the smooth bend of the bend, extensive areas of coastal destruction are observed. The process is complicated by a developed ravine-girder network. During the monitoring period, a displacement of the coast by an average of $0.7 \mathrm{~m}$ was revealed, in some parts of the coast up to $0.9 \mathrm{~m}$. The processes of destruction of the coast threaten the integrity of a number of non-residential and residential buildings, infrastructure facilities.

The bottom of the studied water bodies and coastal shallows are littered with scrap metal. Large sunken ships and barge hulls are observed in the villages of Mys Kamennyj, Novyj Port, Salemal. The ecological situation with littering and pollution of water protection zones and coastal protection zones is assessed as unsatisfactory. In the coastal strips of all water bodies littering with scrap metal, wood and construction waste, and household waste was noted. The location of containers with fuels and lubricants, building materials, parking lots, etc. is fixed. The placement and storage of hazardous materials is observed in the immediate vicinity of the eroded banks. The total area of littered territories within the monitoring sites is $141150 \mathrm{~m}^{2}$, the volume of litter is about $66635 \mathrm{~m}^{3}$.

The data of hydrochemical monitoring showed that the chemical composition of watercourses is typical for the unpolluted surface waters of Western Siberia and is determined by the specifics of natural and climatic conditions. The concentration of most of the indicators is below the values of the maximum permissible concentrations and is consistent with the regional background values for the Yamal Peninsula $[6,7,8,9,10]$.

Based on the results of a comprehensive assessment of the state of surface waters, calculation of the specific combinatorial index of pollution, it was established that the 
monitoring points of the $\mathrm{Ob}$ river (Nadym $\mathrm{Ob}$ ) and the Yangut canals are characterized as "relatively clean" and "slightly polluted" and belong to the 1 st and 2nd quality class. The points of sampling of surface waters of the Seyaha River are characterized as "slightly polluted" and "polluted" and belong to the 2nd and 3rd class of water quality. The natural waters of the Ob Guba (the villages of Novyj Port and Mys Kamennyj) are classified as "polluted" - quality class 3 and "dirty" - quality class 4.

The bottom sediments of the controlled watercourses are characterized by a neutral reaction of the environment, with a low content of chlorides, sulfates, nutrients, as well as organic and synthetic compounds. The concentration of detectable heavy metals is below the level at which a negative impact on benthic systems is observed. The level of oil products in the bottom sediments of watercourses does not exceed the threshold of $100 \mathrm{mg} /$ $\mathrm{kg}$. Based on the results of calculating the total indicator of the pollution of bottom sediments, it was found that the bottom sediments of the study area are characterized by a "low level of pollution".

According to the results of biotesting, surface waters and bottom sediments of monitored streams do not have a toxic effect on test objects in the context of all studied sections of channels, which indicates the general well-being of aquatic ecosystems.

\section{Conclusion}

The chemical composition of watercourses is typical for the unpolluted surface waters of Western Siberia and is determined by the specific nature and climatic conditions. The concentration of most of the indicators is consistent with the regional background values for the Yamal Peninsula. The results of environmental monitoring of water bodies indicate that the hydrochemical composition is more or less stable before and after settlements. Comparable values of the monitored indicators were noted, both in the conditional background and control sections, the range of concentration variation is not significant. The content of pollutants and heavy metals is mainly determined by natural conditions.

Under the conditions of a changing climate, exogenous processes of relief formation become more active, and active channel deformations are recorded in the studied areas. Permafrost rocks of light granulometric composition, which are composed of the banks, are subject to abrasion processes. In some cases, the situation is complicated by the development of a ravine-girder network. Coastal destruction processes threaten the integrity of residential and non-residential buildings, infrastructure facilities.

The coastal strips of all reservoirs are littered, a large number of large and mediumsized dumps of scrap metal, wood, construction and household waste are recorded. Most of the ravines and drainage hollows are littered with debris. In the hollows, there is a planar washout and runoff from the territory of the dumps.

To improve the environmental situation, it is necessary to take measures aimed at reducing a significant negative impact on environmental components within the water protection zones and coastal protective belts, as well as bank protection and anti-erosion work.

\section{References}

1. L.V. Larchenko, R.A. Kolesnikov, L. Mukhametova, E3S Web of Conferences 161, 01006 (2020)

2. L.V. Larchenko, R.A. Kolesnikov, Int. J. Eng.\&Techn. 7(3), 369-375 (2018)

3. E. Agbalyan, A. Krasnenko, E. Shinkaruk, E3S Web of Conferences 169, 01001 (2020) 
4. E.V. Agbalyan, R.A. Kolesnikov, A.S. Krasnenko, E.N. Morgun, E.V. Shinkaruk, A.S. Pechkin, R.I. Loktev, R.M. Ilyasov, V Kobelev, Water Sector of Russia: problems, technologies, management, 6, 6-23 (2019)

5. E.N. Morgun, R.A. Kolesnikov, E.V. Agbalyan Program of Integrated Scientific Environmental Monitoring of the Yamalo-Nenets Autonomous Okrug (EDP, Geographer, Salekhard, 2019)

6. N. Yurkevich, O. Saeva, N. Yurkevich, R. Kolesnikov, T. Kuleshova, IOP 20th International Multidisciplinary Scientific GeoConference SGEM, 423-430 (2020)

7. E. Shestakova, I. Fedorova, R. Loktev, R. Kolesnikov, N. Alexeeva, 18th International Multidisciplinary Scientific GeoConferences SGEM, 18(1.5), 517-524 (2018)

8. D.V. Moskovchenko, Geography and natural resources, 1, 35 (2003)

9. E.V. Agbalyan, E.V. Shinkaruk, Int. J. Applied and Basic Res., 6-3, 457-459 (2015)

10. N.V. Yurkevich, O.P. Saeva, V.V. Olenchenko, A.I. Sinickij, Interekspo Geo-Sibir', 2(3), 150-155 (2017) 